\title{
ORBITAL CAVERNOUS HAEMANGIOMA: Transnasal Endoscopic Surgical Management - A case report
}

\author{
Dr. Mohammad Idrish Ali ${ }^{1}$, Prof. Sheikh Hasanur Rahman ${ }^{2}$, Prof. Kamrul Hassan Tarafder ${ }^{3}$, Dr. Mohammad \\ Rokon Uddin Bhuiyan ${ }^{4}$.
}

1. Consultant, Department of Otolaryngology-Head \& Neck Surgery, Bangabandhu Sheikh Mujib Medical University, Shahbag, Dhaka, Bangladesh.

2. Professor, Department of Otolaryngology-Head \& Neck Surgery, Bangabandhu Sheikh Mujib Medical University, Shahbag, Dhaka, Bangladesh.

3. Professor, Department of Otolaryngology-Head \& Neck Surgery, Bangabandhu Sheikh Mujib Medical University, Shahbag, Dhaka, Bangladesh.

4. Assistant Professor, Kurmitola General Hospital, Dhaka, Bangladesh.

\begin{abstract}
Address of correspondence: Dr. Mohammad Idrish Ali, MBBS, MS (ENT), Consultant, Department of Otolaryngology-Head \& Neck Surgery, Bangabandhu Sheikh Mujib Medical University, Shahbag, Dhaka, Bangladesh. Email: dridrishalient72@gmail.com, Mob: +8801712790646.
\end{abstract}

DOI: $10.31364 / S C I R J / v 7 . i 9.2019 . P 0919699$

http://dx.doi.org/10.31364/SCIRJ/v7.i9.2019.P0919699

\section{Introduction:}

Cavernous haemangiomas (CHs) are the most common intraorbital tumours found in adults. This tumour occurs in females more frequently than in males and its peak incidence is in early middle age $\mathrm{e}^{3,4}$ and it may enlarge during pregnancy ${ }^{4,5}$. They can encroach on intraorbital or adjacent structures and be considered anatomically or positionally malignant. ${ }^{1,2}$

Most of these tumours are unilateral and can increase intraorbital volume with a resultant mass effect1. The clinical hallmark is a slowly progressive, painless proptosis, but patients may also present with loss of vision either due to optic nerve compression or hyperopic shift when the mass compresses the posterior pole. In the later case, choroidal folds may be seen on fundus examination.

Most orbital cavernous haemangiomas require no intervention, but especially when vision is compromised surgery is indicated.

The approach is dictated by tumour location within the orbit. The typical described approaches are lateral orbitotomy, transconjunctival and frontotemporal ${ }^{1,3}$. We present a case of an orbital $\mathrm{CH}$ with visual compromise and its transnasal endoscopic surgical management.

\section{Case report:}

A 34 year-old female patient presented with slowly progressive proptosis of the left eye ball for last 2 years and impairment of vision and headache during last 4 months. On examination visual acuity was 6/9 in the left eye and 6/6 in the right eye with normal colour vision and pupilary reflexes. Foundoscopy revels normal disc in right eye and slightly blurred in the left eye, choroidal folds tempered to disc and venous pulsation present in left eye, there was no collateral vessels.

CT scan with IV contrast showed a oval homogeneously enhancing isodense mass in the left retrobulbar region extending from the orbital apex to the posterior pole of the left eye ball, causing mild proptosis, No evidence of bony erosion or intracranial extension.

After careful preoperative evaluation and proper counseling an endoscopic transnasal resection of the lesion was planned and informed consent was taken.

With all possible aseptic precaution under general anaesthesia, the left uncenectomy and left ethmoidectomy were performed. Lemina papyraecia was identified and removed. Incision was made in the periorbital. Then medial rectus was identified by blant discection which was then retracted for expose the medial conal space.

After careful dissection, a bluish oval lobulated swelling was identified in the conal space and removed carefully using blant descection and careful bipolar electrocautry. Antibiotic lubricated pack was given in the nasal cavity which was removed after 48 hours. Histopathological examination confirmed, cavernous haemangioma.

Endoscopic examination and nasal cleaning was done on $2^{\text {nd }}, 7^{\text {th }}, 14^{\text {th }}$ and $30^{\text {th }}$ postoperative days.

Postoperatively patient developed sub-conjunctival haemorrhage and a periorbital acymosis which gradually disappeared. 
There was restricted movement of the medical rectus which improved gradually.

On $3^{\text {rd }}$ postoperative day vision of the both eye was $6 / 6$ and fundoscopy revealed was normal findings.
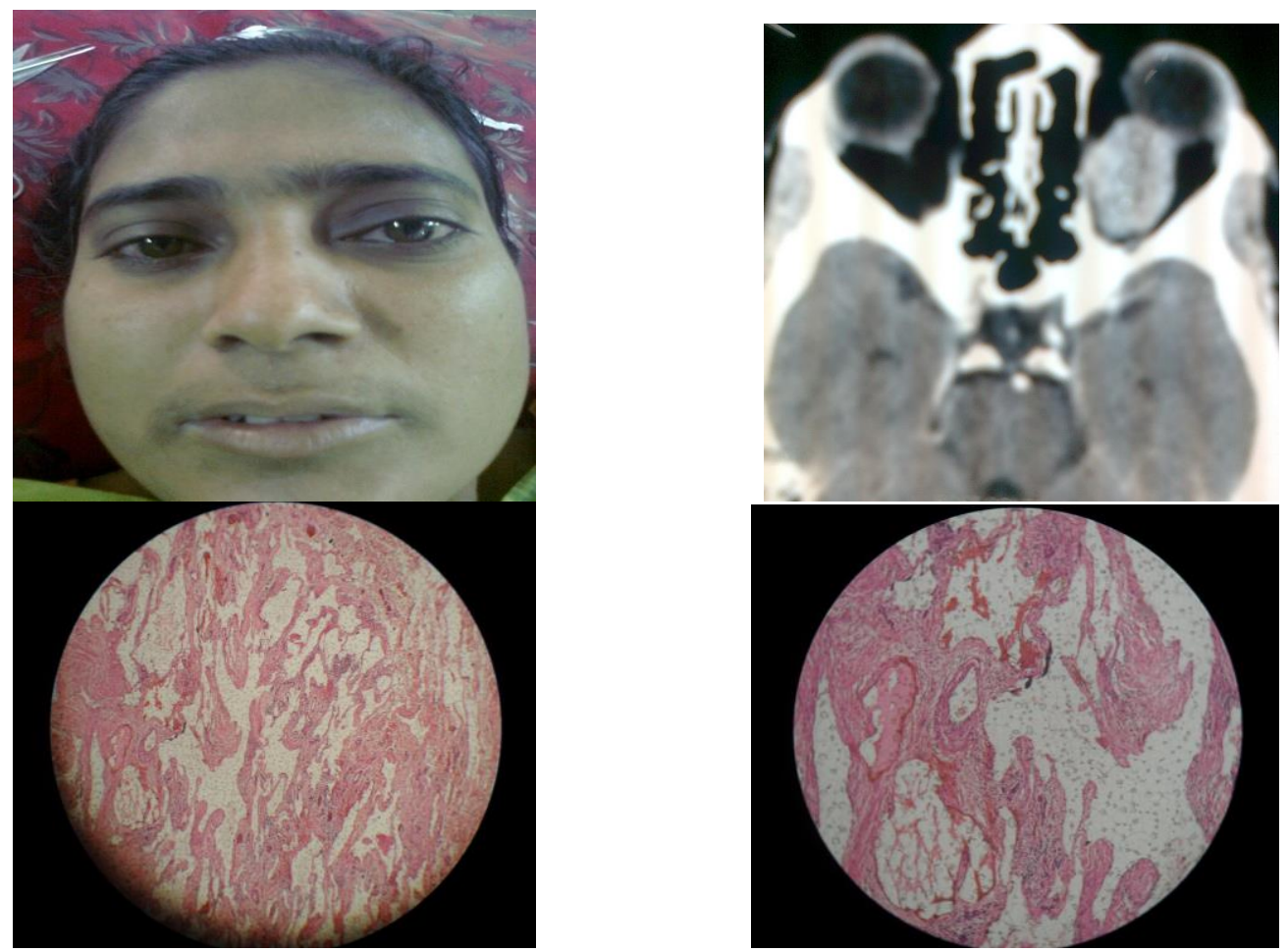

\section{DISCUSSION}

The cavernous haemangioma is one of the most common primary orbital tumours. This tumour occurs more frequently in female and has its peak incidence is in the early middle age ${ }^{3}$ and it may enlarge during pregnancy ${ }^{4}$.

Painless and progressive reducible unilateral proptosis causing a variable degree of hyperopia is the usual clinical presentation ${ }^{5,6}$ and amaurosis fugax can occur ${ }^{7}$. Multiple cavernous haemangiomas are rare but can occur simultaneously or be separated by long intervals. ${ }^{3,8}$

Schwannomas are encapsulated and usually have a slow-growing and noninvasive character. They also can cause exophthalmos, optic neuropathy and diplopia, like cavernous hemangiomas ${ }^{9,10}$. It is difficult to differentiate these conditions clinically.

Histologically cavernous haemangioma is quite different from capillary haemangioma of the orbit ${ }^{8}$ and it is not considered likely that it arises by cavernous transformation of a capillary tumour present undetected from infancy ${ }^{2}$. Unlike capillary haemangiomas, orbital cavernous haemangiomas are discrete, well encapsulated tumours without large vascular tributaries ${ }^{9}$, large and small thin walled cavernous vessels identical to those within an orbital cavernous haemangioma have been found lying outside the tumours capsule.

He et al. ${ }^{11}$ reported the histopathologic classification and distribution of orbital diseases in 3476 patients. They reported that the 10 leading diseases were cavernous haemangioma, leiomyoma, inflammatory pseudotumor, dermoid, schwannoma, meningioma, benign mixed tumour of the lacrimal gland, mucocele, varix and lacrimal gland epithelial tumour. Except for the cavernous hemangioma and schwannoma, all the tumours have distinct characteristics features and usually can be identified using conventional MRI.

CT, MRI and echography have all been studied for the evaluation of cavernous hemangioma ${ }^{3,5}$. Choice of imaging depends on clinical suspicion, but the authors feel that CT with contrast is a good first choice of this will yield information about the shape, vascularity, consistency and margins of the lesion as well as adjacent bony changes. ${ }^{3}$ Some studies report that MRI can be helpful in differentiating between schwannoma, hemangiopericytoma and cavernous hemangioma 5 .

CT appearance- well defined oval or rounded mass roughly isodense to muscle. Hyperdense areas within the lesion may correspond to areas of thrombosis 'phleboliths' contrast enhancement is homogenous but fills slowly.

In summary, lesions are easiest to see either on non-contrast-enhanced $\mathrm{T}_{1}$ images without fat suppression, fat-suppressed $\mathrm{T}_{2}$ image, or $\mathrm{T}_{1}$ fat-suppressed contrast enhanced images ${ }^{6,3}$.

In this study a lentiform homogenously enhancing isodense mass is noted in left retrobulbar region extending from the apex to the posterior wall of the left eye ball, causing mild proptosis. 
Surgery for lesions of the orbital apex are notable for their complexity because access and visualization of the tumours, as well as their removal is limited by the compact bony boundaries and delicate neurovascular environment of the orbital apex. The risks of surgery include haemorrhage form the ethmoid arteries and the potential for injury to the optic nerve with resultant blindness.

Although cavernous hemangiomas are benign vascular tumours that can be relatively indolent and painless, their precarious location can cause serious morbidity. Tumours in the orbital apex can cause proptosis, and visual disturbances typically occur late in their course as a result of tumour growth.

Approaches of the $\mathrm{CH}$ depends on location of the tumours. External approaches provide direct exposure of the lesion, they are associated with significant morbidity, more bleeding and external scar. The typically described approaches are lateral orbitotomy, transconjuctival and frontotemporal. There are very few reported case of endoscopic transnasal resection of the intraorbital lesions. An endoscopic transnasal approach, which requires no skin incision, is a minimally invasive surgery, leading to excellent cosmetic results with less bleeding. It gives good illumination and magnified vision of surgical field.

\section{Reference:}

1. Cohen AJ, Mercandetti M, Weinberg DA. Hemangioma, cavernous (Aug 2008). Available at http://emedicine.medscape.com/article/1218120-overview. Accessed March 11, 2009.

2. Harris GJ, Jakobiec FA. Cavernous hemangioma of the orbit. J Neurosurg 1979; 51: 219-228.

3. Dinakar I, Naik RT, Purohit AK, Ratnakar KS. Cavernous hemangioma of the orbit: A case report, Indian J Pathol Microbiol 1993; 36: 318-321.

4. Wilms G, Raat h, Dom R, et al. Orbital cavernous hemangioma: findings on sequential Gd-enhanced MRL J Comput Assist Tomogr 1995; 19:548-51.

5. Scheuerle AF, Steiner HEPATITIS, Kolling G, et al. Treatment and long-term outcome of patients with orbital cavernoumas. Am J Opthalmol 2004; 138: 237-44.

6. Ruchman MC, Flanagan J. Cavernous hermangiomas of the orbit. Ophthalmology 1983; 90: 1328-1336.

7. D'Hermies F, Elmaleh C, Mourier K, et al. Cavernous hemangioma of the orbit (in French). JFrOphtalmol 1993; 16: 195198.

8. Brown GC, Shields JA. Amaurosis fugax secondary to presumed cavernous hemangioma of the orbit. Ann Ophthalmol 1981; 13: 1205-1209.

9. Dervin JE, Beaconsfield M, Wright JE, Moseley IF. CT findings in orbital tumours of nerve sheath origin. Clin Radiol 1989; 40: 475- 479 .

10. Carrol GS, Haik BG, Fleming JC, Weiss RA, Mafee MF. Peripheral nerve tumors of the orbit. Radiol Clin North AM 1999; 37: 195- 202.

11. Iwamoto T, Jakobiec FA. Ultrastructural comparison of capillary and cavernous hemangiomas of the orbit. Arch Ophthalmol 1979; 97: 1144-53. 